\title{
DE GRENZEN VAN HET KUNNEN
}

\section{door J. A. Burggraaff}

De titel van dit opstel roept herinneringen op aan discussies welke rondom de oprichtingsdag van dit tijdschrift werden gevoerd, een woordenstrijd waaraan de namen Sternheim, Limperg, Dijker verbonden zijn, in latere fasen versterkt met Reder, Belle, A. Mey en vele anderen. Behoort die gedachtenwisseling geheel tot de geschiedenis, of heeft zij vandaag nog betekenis? Laten wij eerst eens bekijken waar het over ging.

\section{Historie I}

Onderwerp van de discussie was de vraag, of er een norm is voor de controlearbeid, door de accountant te verrichten ter uitvoering van een opdracht, en zo ja, waarin die norm zou kunnen worden gevonden.

In aansluiting op eerdere discussies betrok Sternheim in 1924 zijn stellingen. $\mathrm{Na}$ te hebben gesteld dat de accountantscontrole ten doel heeft een basis te verkrijgen waarop decharge kan worden verleend, wees hij de originele bescheiden en aantekeningen en de wijze hunner verwerking als object van onderzoek aan. Aan deze arbeid zijn, zo meende hij, ,,slechts de natuurlijke grenzen van het menselijk kunnen te stellen, want het dragen van verantwoordelijkheid eist de gehele persoonlijkheid van de accountant op". Nader sprekende over het verantwoordelijkheidsbegrip wijst hij er op dat dit mede wordt bepaald door de omstandigheden waaronder de accountant arbeidt, en dat begrenzing slechts mogelijk is door onderlinge afspraak der accountants. Ook de opdrachtgever kan een beperking in de verantwoordelijkheid aanbrengen. Uit de verdere uitwerking van Sternheim blijkt, dat naar zijn inzicht een volledige controle van alle verrichte boekingen vereist is, dat de accountant alles moet controleren waartoe hij bij machte is. Al komen wij dan hier en daar wel een passage tegen in de trant van ,Hoever de accountant moet gaan, zal afhangen van de omstandigheden en van zijn verantwoordelijkheidsbegrip".

Het onderwerp werd in 1926 door Limperg op een iets andere wijze benaderd. Sprekende over de verantwoordelijkheid van de accountant onderkende hij een verband tussen achtereenvolgens doelstelling van het onderzoek, strekking van de verklaring, verantwoordelijkheid van de accountant, en te verrichten arbeid. De doelstelling van het onderzoek gegeven zijnde, is het aan de accountant vast te stellen welke arbeid overeenkomstig de vaktechnische eisen moet worden verricht om de doelstelling te verwezenlijken. Limperg keerde zich met deze uiteenzetting tegen hen, die meenden dat de opdracht (en derhalve de opdrachtgever) een constituerend element in de te verrichten arbeid mocht zijn: zij wijst slechts de doelstelling van het onderzoek aan. Limperg gaat in zijn betoog niet in op wat de te verrichten arbeid in concreto omvat, noch op de vraag of de accountant bij machte zou zijn de vereiste arbeid te verrichten. Zijn pleidooi om de controle niet beperkt te 
zien als slechts gericht op boekhoudkundige juistheid, doch ruimer en gericht op de volledigheid der verantwoording en de oorzaken der bedrijfsuitkomsten, wekt evenwel de impressie dat Limperg zich stelt achter Sternheim's conceptie van de volledige controle.

Het was Dijker, die in 1927 tegen deze conceptie verzet aantekende. Hij constateerde een wijde kloof tussen datgene wat de theorie leert en datgene wat in de praktijk wordt waargenomen. Terwijl de theorie uiteenzet welke arbeid moet worden verricht om maximale zekerheid te verschaffen, legt de praktijkbeoefenaar zich substantiële beperkingen op, gebaseerd op zijn subjectief verantwoordelijkheidsbegrip en daardoor ,kunstmatig” van karakter. De theorie krijgt van Dijker het verwijt, dat zij zich teveel occupeert met de vraag, op welke wijze maximale zekerheid kan worden verkregen; de praktijk wordt vermaand dat de in acht te nemen beperkingen niet op subjectieve inzichten mogen stoelen, hetgeen er toe kan leiden dat er te weinig arbeid wordt verricht. De beperking moet geobjectiveerd worden tot een „,natuurlijke": de beperkingen die het beroep - gezien zijn positie in het bedrijfsleven - in de praktijk als minimum aanvaardbaar acht zonder dat de goedkeurende verklaring buiten bereik komt te liggen. Deze natuurlijke beperking zou door de beroepsorganisatie moeten worden vastgesteld als gemiddelde van wat blijkens een enquête door de beroepsbeoefenaren in de praktijk aan arbeid word t verricht. De aldus verkregen normen moeten worden bekend gemaakt ten dienste van beroepsuitoefening, onderwijs en rechtspraak.

In deze gedachtengang kunnen theoretische beschouwingen leiden tot verdieping van inzicht, en op den duur wellicht ook tot verhoging van normen, maar wordt de beroepsuitoefening-van-vandaag bepaald door wat de accountants-van-vandaag als behoorlijke praktijk erkennen. De grenzen van het kunnen komen bij deze beschouwing niet aan de orde. Het is van belang hier op te merken, dat Dijker's zienswijze niet alleen betrekking had op normen voor de te verrichten arbeid, maar evenzeer op normen waaraan een jaarrekening heeft te voldoen. Terwijl Dijker's pleidooi voor het eerste stel normen vergeefs is geweest, heeft zijn betoog voor het tweede stel meer dan 40 jaar later een begin van uitvoering gekregen.

Dijker's roep om ,"natuurlijke beperking” en om codificatie van de te verrichten arbeid viel blijkens het op zijn voordracht gevolgde debat niet bij ieder in goede aarde. In 1927 ondernam Reder een poging tot concretisering der vereiste controle-arbeid, uitgaande van de in 1926 door Limperg geponeerde beginselen. Reder rekent in zijn betoog af met de conceptie der volledige controle: slechts die arbeid moet worden verricht die noodzakelijk is voor de te verwezenlijken doelstelling; waar mogelijk dient volledige detailcontrole vervangen te worden door totalencontroles; het doel moet met zo gering mogelijke offers worden bereikt. De grenzen van het kunnen zijn in Reder's gedachtengang, zo moet men concluderen, geen bepalend element voor de te verrichten arbeid. Terzijde moge worden opgemerkt, dat Reder in het hier besproken betoog het steunen op interne controle afwijst; een aspect dat elders in deze M.A.B.-jaargang behandeling vindt. 
In 1930 grijpt Dijker opnieuw de pen om de ,volledige" controle à la Sternheim, leidend tot "100\%"-zekerheid, aan critiek te onderwerpen, en tevens de houdbaarheid van Reder's stellingen te bestrijden. Hij betoogt, dat een onderzoek overeenkomstig Reder's vaktechnische eisen niet tot $100 \%$-zekerheid kan leiden, en dat die zekerheidsgraad slechts bereikbaar zou zijn via een volstrekt-volledig onderzoek, met inbegrip van mede-ondertekening van pandbrieven, polissen, e.d., vaststelling van grootte en kwaliteit van voorraden op de balansdatum enz. Naar zijn mening wordt dit een onuitvoerbaar programma, wekt de verklaring niet de verwachting dat een dergelijk programma zou zijn uitgevoerd, en moeten de laatste procenten zekerheid worden afgewogen tegen de aanzienlijke kosten die daarvoor moeten worden gemaakt.

In het verdere van zijn betoog leidt Dijker de beperkingen, die de accountant zich ten opzichte van de $100 \%$-zekerheid mag veroorloven, af uit de doelstelling van het onderzoek. Voorzover die doelstelling is gelegen in de afgifte van een verklaring bij een te publiceren jaarrekening - door hem aangeduid als: publieke taak - onderschrijft Dijker de opvatting van Limperg, dat de taak voortvloeit uit het gewekte vertrouwen. Hij verbindt daaraan de klacht dat de inhoud van dat vertrouwen nu juist de kardinale vraag is waarop Limperg het antwoord schuldig bleef. Ligt de doelstelling in een rapport voor beperkte kring (43 jaar later plotseling een hoogst-moderne vakterm ...) dan kunnen opdrachtgever en accountant onderling de taak, en daarmede de verantwoordelijkheid, van de accountant overeenkomen. Dijker noemt dit de private taak, waarbij de opdrachtgever verder of minder ver kan gaan dan in de publieke taak is vereist, daarbij de kosten afwegende tegen de te verkrijgen graad van zekerheid.

Deze ,nut-en-offer-theorie" werd door Belle in 1931 verder uitgewerkt. Wij laten deze beschouwingen, evenals de daarop geoefende critiek, hier onbesproken. Volstaan moge worden met te constateren, dat Belle Sternheim's stelling, ,dat aan de controle-arbeid slechts de natuurlijke grenzen van het menselijk kunnen te stellen zijn" afwijst als zijnde een ontkenning der economische wetmatigheid: de grenzen liggen daar waar verdere arbeid irrationeel wordt. Ook Limperg ontkwam niet aan Belle's critiek; hij betoogt dat Limperg's visie geen ruimte laat voor een op economische gronden geboden relativering in de te verschaffen zekerheid, en daardoor onvermijdelijk terecht moet komen bij Sternheim's natuurlijke grenzen van het menselijk kunnen.

In 1932-1933 zette Limperg in een breedvoerige, onvoltooid gebleven, artikelenserie zijn denkbeelden nader uiteen. Hij bespreekt het verband tussen algemene functie, specifieke functies, behoeften van het verkeer, stand der controletechniek en te verrichten taak. Kort gezegd komt zijn zienswijze er op neer, dat de arbeid, te verrichten in de specifieke functie, zodanig moet zijn dat het vertrouwen van het maatschappelijk verkeer, opgewekt door het optreden in de algemene functie, niet wordt beschaamd. Dat vertrouwen wordt, wat de verlangde graad van zekerheid betreft, bepaald door de ratio-

$m a b$ blz. 82 
nele verwachtingen van de verstandige leek, als resultante van enerzijds de behoeften aan zekerheid, anderzijds het vermogen van de controletechniek om in die behoeften te voorzien. Deze zienswijze, ook wel leer van het gewekte vertrouwen of vertrouwenstheorie genoemd, leidt tot de conclusie, dat de graad van zekerheid te verwezenlijken in de specifieke opdracht, een afgeleide is van de algemeen-geldende norm, welke op haar beurt voortkomt uit de wisselwerking tussen behoeften van het verkeer en vaktechniek, welke beide aan evolutie onderhevig zijn. De norm voor de te verschaffen zekerheid - en daardoor tevens die voor de te verrichten arbeid - is daarmede onttrokken aan de wil van de individuele opdrachtgever en evenzeer van de individuele accountant, zij komt tot stand in een collectief proces onder invloed van maatschappelijke behoeften enerzijds, prestatievermogen van het beroep anderzijds. Limperg erkent, dat die norm nergens zwart op wit staat gegeven; alsook dat in tijden van evolutie in behoeften en mogelijkheden er onzekerheid t.a.v. de norm kan bestaan. Het is aan de accountant om, de inhoud van de specifieke functie gegeven zijnde - en bij tal van specifieke functies ligt die zodanig vast dat van een geconsolideerde functie kan worden gesproken zich te realiseren waar die norm ligt, en vervolgens te besluiten welke arbeid vereist is om aan die norm te voldoen.

Een onderzoek, aldus opgezet en derhalve gericht op een doeltreffende vervulling van de specifieke functie, wordt aangeduid met de term ,,volkomen controle", zulks in onderscheid van een alle boekingen omvattende ,,volledige controle".

Limperg wijst af, dat de accountant volkomen $100 \%$-zekerheid zou dienen te verschaffen. Dit zou technisch reeds onmogelijk zijn, gezien des accountants beperkingen als mens; het zou ook irrationeel zijn, omdat , het verkeer zoveel van de volkomen zekerheid moet prijsgeven dat het resultaat der controle de kosten loont". In zijn betoog neemt Limperg afstand van Sternheim's ,natuurlijke grenzen van het menselijk kunnen", en gaat tevens in tegen Dijker's opvatting dat in de private taak opdrachtgever en accountant de taak kunnen overeenkomen.

In 1936 deed $A$. Mey een poging om de vaktechnische eisen voor de te verrichten arbeid nader te preciseren. Hij introduceerde de hypothese van een administratie en interne controle die aan alle eisen voldoet, onderzocht wat de taak van de accountant als minimum-programma bij die hypothese is, alsook wat aan aanvullende arbeid moet worden verricht indien aan de hypothese niet wordt voldaan. De grenzen van het kunnen komen in Mey's betoog niet meer aan de orde.

Met dit onvolledige en summier overzicht van de historie moge worden volstaan.

\section{Historie II}

$\mathrm{Er}$ is met betrekking tot de grenzen van het kunnen ook nog een andere ontwikkelingsgang waarneembaar.

Vroegere generaties van beroepsgenoten hadden er reeds een open oog 
voor, dat het verschaffen van zekerheid aangaande de juistheid ener verantwoording aan de accountant eisen stelt waaraan hij niet kan voldoen, hetzij omdat zij een technische deskundigheid impliceren welke de accountant niet bezit, hetzij omdat eventuele onjuistheden en omissies door het onderzoek der administratie niet aan het licht kunnen worden gebracht. Het kunnen van de accountant vindt zijn grens daar waar zijn deskundigheid ophoudt, en daar waar de reikwijdte van de hem ten dienste staande middelen tot het blootleggen der werkelijkheid eindigt. Dit aspect speelt door de in Historie I gereleveerde beschouwingen heen; zo b.v. bij Dijker die in het gebrek aan technische deskundigheid reden zag om physieke voorraadopname als vaktechnische eis af te wijzen.

In de beroepsregelen van het N.I.v.A., zoals die destijds luidden, was deze begrenzing met zoveel woorden tot uitdrukking gebracht. Het toenmalige Reglement van Arbeid bevatte de volgende bepalingen:

- De goedkeuring van de balans strekt zich ten opzichte van het bestaan der koopmansgoederen en gebruiksbezittingen, zomede ten opzichte van de waardering dier goederen en de afschrijvingen op die bezittingen niet verder uit dan van de niet-ter-zake-kundige verlangd mag worden (art. 7).

- De leden zijn niet verantwoordelijk voor omissiën, welke het onderzoek der administratie niet aan het licht kon brengen (art. 5).

Deze beperkingen, veelal aangeduid als natuurlijk of axiomatisch voorbehoud, zijn in de literatuur nog enkele malen aan de orde geweest, en dan in het bijzonder toegespitst op de vraag, of een voorbehoud van deze aard in de verklaring tot uitdrukking zou moeten worden gebracht.

J. Polak meent in 1928 van niet: een deskundigenverklaring is een mededeling over gegevens die en voorzover zij binnen het deskundigheidsgebied liggen. Zo objectief vaststaat dat gegevens buiten het terrein der deskundigheid liggen, en het onderzoek naar vaktechnische eisen is uitgevoerd, is er geen plaats voor een voorbehoud. Immers, het onderzoek vertoonde geen leemten, en bracht geen onjuistheden aan het licht.

Limperg ${ }^{1}$ ) meende in 1946 niet alleen, dat vermelding in de verklaring overbodig was, maar ook dat de aangeduide bepalingen uit het Reglement van Arbeid verwijderd moesten worden. Naar zijn oordeel had het maatschappelijk verkeer thans voldoende zicht op wat wel en wat niet van de accountant mocht worden verwacht, zodat de onderhavige artikelen overbodig en daarom ongewenst waren. Hij vond bijval, en bij de reglementsherziening van 1946 werden de betreffende bepalingen geschrapt.

Dat overigens de beperkingen voortvloeiende uit het axiomatisch voorbehoud niet een zodanige omvang mogen aannemen dat het resterende veld van onderzoek een te smalle basis zou gaan vormen voor de accountantsverklaring, werd reeds eerder uiteengezet, o.m. door Limperg in 1940.

$\mathrm{Na} 1946$ komt men het axiomatisch voorbehoud in de literatuur weinig meer

1) De Accountant, Sept. 1946, pag. 81

$m a b$ blz. 84 
tegen. Van Rietschoten voert het in een van zijn artikelen en passant ten tonele, Kleerekoper wijdt er één alinea aan, Nordemann stipt het even aan. De discussie lijkt gesloten.

\section{Zijn er grenzen aan het menselijk kunnen?}

Wie de ontwikkeling van een halve eeuw overziet kan niet anders concluderen dan dat de grenzen van des accountants kunnen aanmerkelijk zijn verruimd. Om enkele factoren daarin te noemen:

1 De ontwikkeling van de boekhouding van toen tot het bestuurlijk informatiesysteem van heden geeft de accountant meer mogelijkheden verschijnselen waar te nemen, zowel datgene wat uit de toon valt en daarom nadere beschouwing verdient, als datgene wat de verklaring bevat van iets dat hem eerder als merkwaardig of onverklaarbaar was opgevallen. Het "oplossend vermogen" van het instrument, waarvan de accountant zich bedient ter waarneming van het bedrijfsgebeuren, is toegenomen.

2 Nieuwere inzichten ten aanzien van de betekenis der interne organisatie en controle voor de accountant - een onderwerp dat elders in deze jaargang behandeling vindt - geven de accountant een betere greep op de volledigheid der verantwoording en daarmede een hechtere waarborg tegen ,omissiën welke het onderzoek der administratie niet aan het licht kan brengen".

3 De evolutie der controlemiddelen, en met name ook de toepassing daarin van wiskundige methodieken, geeft de accountant van heden meer mogelijkheden tot analyse, interpretatie en evaluatie dan zijn beroepsgenoot van 50 jaar geleden ter beschikking stonden. De eigen actie - ook dit onderwerp komt elders in deze jaargang aan de orde - kan daardoor thans verder reiken dan voorheen.

4 De ordening van beroepsgenoten in grotere eenheden schept mogelijkheden tot verbijzondering op deelgebieden, waardoor de eenheid in kennis, en daarmede in kunnen, méér kan opbrengen dan de enkeling vermag en vermocht. De mogelijkheden daartoe zijn recent verder verruimd, doordat thans ook deskundigheden welke buiten de traditionele grenzen van het accountantsberoep liggen, in de eenheid mogen worden opgenomen.

Anderzijds moet er op gewezen worden dat de "gap" tussen datgene wat de accountant kent en kan, en datgene wat hij zou moeten kennen en kunnen om volkomen zekerheid te verschaffen, de neiging heeft groter te worden. Factoren die daartoe bijdragen zijn:

1 De technologische ontwikkeling heeft het aanzien gegeven aan processen en produkten, die voor de niet-ter-zake-kundige volstrekt onbegrijpbaar resp. ondetermineerbaar zijn. De zorgen rondom de voorraadopneming waarover de accountant van 50 jaar terug zat te tobben, vallen in het niet bij de problemen die zijn vakgenoot-van-vandaag ontmoet b.v. in de chemische of electronische industrie.

2 Moderne informatiesystemen zijn dikwijls geautomatiseerd, niet zelden onder toepassing van zeer complexe apparatuur en programmatuur. De 
mogelijkheden van de accountant kunnen dan aan beperking onderhevig zijn, enerżijds doordat niet alle gegevens op het door de accountant gewenste tijdstip in leesbare vorm worden geproduceerd, anderzijds doordat de accountant - zo hij zich daartoe niet in het bijzonder heeft bekwaamd of zich de daartoe vereiste deskundigheden niet op andere wijze heeft geassumeerd - de werking van het systeem niet in zijn volle omvang kan doorzien, en de daarin schuilende leemten niet kan onderkennen.

3 Tegenwoordig worden in het kader der periodieke financiële informatie mededelingen verlangd omtrent handelingen en gebeurtenissen, welke zich kunnen voordoen los van de kringloop der normale operaties in de verslagperiode. Men denke aan afgegeven garanties, of aan gebeurtenissen na balansdatum. De ontwikkeling van passende middelen terzake is nog gaande, en geeft soms aanleiding tot heftige debatten. ${ }^{2}$ )

Men moet concluderen, dat het kunnen van de accountant nog steeds een wezenlijke grens heeft. Er is reden om dit met nadruk vast te stellen. Men komt nog al eens beroepsgenoten, met name studerenden, tegen die in de rozige illusie leven, dat een accountantsonderzoek, mits naar vaktechnische eisen verricht, volkomen zekerheid kan geven, behoudens binnen een tolerantie vallende afwijkingen van ondergeschikt belang die het beeld der cijfers niet aantasten. Deze illusie is een gevaarlijke.

Een accountant die zich niet bewust is van zijn beperkingen, die zich niet bij voortduring rekenschap geeft van de vraag waar hij om de tuin kan zijn geleid of bij de neus genomen, komt vroeg of laat voor ernstige teleurstellingen te staan.

\section{Zijn de grenzen van het kunnen relevant?}

Zoals eerder geciteerd, verlangt naar Limperg's oordeel het verkeer geen volkomen zekerheid, omdat het rationele handelen eist dat zoveel van de volkomen zekerheid wordt prijs gegeven, dat het resultaat der controle de kosten loont. Uit de verlangde graad van zekerheid volgen de vaktechnische eisen, de taak.

De norm voor de verlangde zekerheid is, zoals gezegd, niet exact bekend, en bijgevolg liggen ook de vaktechnische eisen niet vast. De oorzaak daarvan is gelegen in de omstandigheid dat ,zekerheid" geen grootheid is die zich voor kwantificering leent.

$\mathrm{Nu}$ kan men, wanneer er een relatie is tussen twee grootheden, de kwantificering naar keuze hanteren bij de ene dan wel bij de andere grootheid. In casu betekent dit dat, zo men er niet in slaagt de norm voor de verlangde zekerheid te kwantificeren, men het beoogde doel desondanks kan bereiken door de norm voor de taak te kwantificeren, in die zin dat beschreven wordt welke controleverrichtingen onder welke omstandigheden normatief vereist zijn. Het heeft dan de schijn dat de relatie wordt omgekeerd, doch de theoretische gedachtengang wordt daardoor niet aangetast: de norm voor de taak

2) Zie o.m. de discussie over „aangeklede saldobiljetten” in M.A.B. 1971/1972.

$m a b$ blz. 86 
wordt zodanig gesteld, dat de - onbepaald gebleven - norm voor de verlangde zekerheid wordt gehonoreerd.

Deze gedachte is niet nieuw, zij werd in feite reeds in 1927 door Dijker naar voren gebracht, zij het dat hij hetgeen in de praktijk ,gemiddeld" werd verricht tot norm wilde verheffen. Accountants maken nu al generaties lang controleprogramma's; wanneer de leer dan stelt, dat niet subjectieve inzichten, doch objectieve vaktechnische eisen de te verrichten arbeid bepalen, dan moet het mogelijk zijn om teruggaande van wat in de praktijk wordt verricht, te komen tot een inventarisatie van de vaktechnische eisen met alle variaties onder invloed van relevante omstandigheden, en vervolgens tot een normstelling.

De gedachte is niet nieuw, de kritiek evenmin. Reeds in 1927 werd betoogd, dat codificatie tot verstarring zou leiden, en de evolutie van het beroep belemmeren; dat de omstandigheden in de praktijk van geval tot geval zó verschillen dat geen algemeen-geldende regels kunnen worden gesteld; dat codificatie het beroep zou devalueren tot het toepassen van een receptenboek. Wij willen thans op deze critiek niet uitvoerig ingaan, doch er op wijzen dat moderne ontwikkelingen op andere gebieden hebben aangetoond, dat gecompliceerde intellectuele besluitvormingsprocessen in hun elementen kunnen worden ontleed, en vervolgens geprogrammeerd. Het valt niet in te zien, waarom het besluitvormingsproces dat leidt tot de vaststelling van een controleprogramma niet op overeenkomstige wijze zou kunnen worden ontleed en geprogrammeerd. Dat de omstandigheden van het geval van invloed zijn op de taak is onbetwistbaar; maar dan zal men die omstandigheden kunnen en moeten determineren en beschrijven, en hun gevolgen voor de te verrichten taak vaststellen. Wij mogen hier wel aan de vergetelheid ontrukken, dat Limperg in $1927^{3}$ ) dan wel bezwaar maakte tegen Dijker's voorstel het ,gemiddelde" uit de praktijk tot norm te verheffen, doch van zijn kant voorstelde te trachten voor bepaalde bedrijven of onderdelen van bedrijven tot een communis opinio aangaande de taak te komen, om vervolgens die communis opinio te codificeren.

Het hecft er lange tijd naar uitgezien, dat het beroep zo al niet formeel dan toch in feite doende was tot een normering in termen van te verrichten arbeid te komen; met name onder invloed van het accountancy-onderwijs, waar op de grondslag van de vertrouwenstheorie de praktische uitwerking in diverse casusposities werd beoefend, groeide allengs een algemeen geldend gedragspatroon. De laatste jaren evenwel is dit gedragspatroon weer in de discussie geraakt, in die mate dat Van Rossem schreef: „Hoe de (verdere) eigen actie in de vele verschillende gevallen zal moeten geschieden, is nimmer algemeen aan te geven". De mist rondom de norm voor het gewekte vertrouwen en de vaktechnische eisen is, zo moet men concluderen, weer toegenomen. Wellicht dat Van Rossem's bijdrage aan deze jaargang de mist wat doet optrekken.

Kon men tot dusver mogelijk nog menen, dat wij het wel zonder expliciete

3) Discussie studievergadering 5 maart 1927, volgend op Dijker's referaat. 
normen voor de taak kunnen stellen, naarmate de internationalisatie van het beroep voortschrijdt en wij, ook in eigen land, met de arbeid van buitenlandse accountants te maken krijgen, wordt het gemis steeds ernstiger. Discussie met buitenlandse beroepsbeoefenaren over de verlangde zekerheidsgraad kan slechts gevoerd worden in termen van te verrichten arbeid. Accountants in andere landen kunnen terzake aan gezaghebbende uitspraken refereren, wij kunnen dat niet. Zulks is te onaangenamer nu bij vele accountants hier te lande de indruk bestaat, dat het niveau van beroepsuitoefening elders lager ligt dan hier. Zo internationale harmonisatie gewenst is - en alleen reeds ter vermijding van een competitie in de vaktechnische eisen lijkt die onontkoombaar - is vastlegging van de door ons gehanteerde vaktechnische normen on ontbeerlijk voor het gesprek met onze buitenlandse collega's.

Het kan de schijn hebben, dat het betoog in deze paragraaf niets te maken heeft met het opschrift. De enige harde, geconcretiseerde norm die wij bezitten is echter die van ,het menselijk kunnen". Wanneer het beroep, zichzelf beschouwend als vertrouwensman van het maatschappelijk verkeer, meent dat het gewekte vertrouwen correspondeert met vaktechnische eisen die minder vèr reiken dan de grenzen van het kunnen, dan rust op het beroep de plicht de gehanteerde norm te kwantificeren, hetzij in termen van verlangde zekerheidsgraad, hetzij in termen van vaktechnische eisen.

Van deze verplichting heeft het beroep zich totdusver niet op bevredigende wijze gekweten. En dan moet men niet verbaasd staan, dat in de maatschappij sommigen verwachtingen koesteren die het beroep niet meent te kunnen of te hoeven honoreren; en anderen na een of meer desillusies aan de accountantsverklaring als waardeloze franje voorbijgaan.

Het wordt tijd dat het beroep zijn normen expliciet stelt, zodat de ,grenzen van het kunnen" kunnen worden geplaatst waar zij behoren: in het museum als een herinnering aan vervlogen tijden.

\section{Literatuur}

L. H. Belle, Grondslagen der accountancy. 2e druk, 1960. Delwel.

R. A. Dijker, Het begrip der naturlijke beperking in de accountantscontrole en de invloed daarvan op de accountantsverklaring. N.I.v.A., studievergadering, 1927.

R. A. Dijker, De ,publieke" en "private" taak van de accountant. M.A.B., 1930, herdrukt in 1924/M.A.B./1960.

I. Kleerekoper, De Accountantsverklaring, bijdrage in bundel Stramien. 1967, pag. 164. Kluwer/Samsom.

Th. Limperg Jr., De betekenis van de accountantsverklaring in verband met de verantwoordelijkheid van de accountant. Rede voor het Internationaal Accountantscongres. 1926.

Th. Limperg Jr., De functie van de accountant en de leer van het gewele vertrouwen. M.A.B., 1932/1933, herdrukt in 1924/M.A.B./1960.

Th. Limperg Jr., Accountantscontrole in het effectenbedrijf. M.A.B., 1940, herdrukt in $1924 /$ M.A.B./1960.

A. Mey, De noodzaak van een normatieve theorie der accountantscontrole als leidraad voor de be roepsuitoefening. N.I.v.A. Accountantsdag 1936. 
H. H. J. Nordemann, De al dan niet geclausuleerde verklaring bij de jaarrekening. M.A.B., 1970, pag. 490.

J. Polak, Het voorbehoud in de accountantsverklaring. N.I.v.A., studievergadering, 1929.

H. R. Reder, De vaktechnische eisen bij de controle-arbeid. N.I.v.A., studievergadering, 1927.

A. M. van Rietschoten, De betekenis van de inteme controle voor de accountantscontrole. M.A.B., 1954, pag. 250.

J. P. van Rossem, De invloed van de interne - in het bijzonder de administratieve - organisatie op de controlemaatregelen van de accountant, die belast is met de controle van de jaarrekening. M.A.B., 1970 , pag. 30.

A. Sternheim, De accountantscontrole. 1961, 3e (bekorte) druk. Delwel. 